\title{
De la transición
}

continua a la

instauración democrática

fallida. El caso de

México en perspectiva comparada* / From

a continuous transition

to a failed democratic

establishment. The

case of Mexico in a

comparative perspective

* Recibido: 15 de agosto de 2012. Aceptado: 25 de agosto de 2012.

Tla-Melaua, Revista De Ciencias Sociales. Facultad de Derecho y Ciencias Sociales. Benemérita Universidad Autónoma de Puebla, México / Issn: 1870-6916 / Nueva Época, Año 6 No 32, Abril - Septiembre 2012, PP. 6-29. 
El presente artículo se entregó al Departamento de Publicaciones de la Facultad de Derecho y Ciencias Sociales el 15 de agosto de 2012. Conviene tener presente el dato porque algunas de sus tesis sólo cobran sentido a la luz de los acontecimientos de esa coyuntura, o sea unas semanas después de las elecciones federales del 2012 y unas semanas antes de que el órgano responsable de calificar las elecciones emita su resolución sobre las mismas, las cuales fueron impugnadas por uno de los contendientes por presuntas irregularidades y violaciones legales.

\section{PALABRAS CLAVE}

Democracia, transición, alternancia, autoritarismo, instauración democrática fallida.
This article was delivered to the Publications Department of the School Of Law and Social Sciences on August 15, 2012. Attention should be drawn to the fact that some of its thesis only make sense in light of the events of that situation; that is a few weeks after the federal elections of 2012 and a few weeks before the legal body responsible for qualifying the election and issuing its resolution, which were contested by one of the contenders for alleged irregularities and legal violations.

KEYWORDS

Democracy, transition, alternation, authoritarianism, and a failed democratic establishment.

\footnotetext{
** Profesor-investigador en la Facultad de Derecho y Ciencias Sociales de la Benemérita Universidad Autónoma de Puebla, México. (politicaparaciudadanos@gmail.com)
} 
I. ¿Por qué fracasan las transiciones?

II. ¿ ¿Restauración autoritaria, regresión o alternancia de regreso?

III. ¿ ¿Regresión pactada o el mundo al revés?

IV. El peso de las decisiones

v. Auto de fe

Sólo desde la ingenuidad más rampante se puede pensar que el TEPJF (Tribunal Electoral del Poder Judicial de la Federación) convalidará el auto de inconformidad interpuesto por el Movimiento Progresista y declarará inválida la elección presidencial de 2012. Sin embargo, conviene tener claro lo que está en juego con el fallo del TEPJF, no sólo para el futuro de la vida política en México sino de la propia democracia.

Que las elecciones presidenciales del 2012 presentaron un sinnúmero de irregularidades es evidente para millones de mexicanos. Los ilícitos e inequidades durante la contienda fueron tan burdos y grotescos que constituyen un agravio a todos los que vivimos en este país, incluidos los que votaron por el candidato virtualmente ganador, o sea por el priista Enrique Peña Nieto, desde la imposición mediática del candidato de la Alianza PRI-PVEM hasta el escabroso caso del Monexgate, pasando por la manipulación de las encuestadoras, la compra indiscriminada de votos a favor de Peña Nieto, el exorbitante uso de recursos para la campaña del prïsta y cientos de irregularidades más.

Fueron tantas y tan evidentes las anomalías que por momentos parecía que estábamos instalados todavía en la era de las elecciones simuladas y ficticias que el PRI montó durante décadas. Más aún, las elecciones del 2012 hacen que las inconsistencias de las elecciones precedentes del 2006 parezcan cosa de niños. La pregunta es, ¿por qué entonces las autoridades judiciales encargadas de calificar las elecciones terminarán convalidando un proceso tan enlodado como éste, recurriendo presumiblemente a todo tipo de argucias legales destinadas a minimizar el peso de las denuncias y apostando a la apatía o docilidad social? La respuesta es obvia, lo que menos interesa a los magistrados de lo contencioso electoral es limpiar una elección llena de irregularidades y mucho menos atender el reclamo de una sociedad agraviada. Al igual que el IFE (Instituto Federal Electoral), cuya actuación en estas elecciones deja mucho que desear en términos de imparcialidad y transparencia, el TEPJF responde a intereses políticos muy concretos, mucho más poderosos que un efímero y poco rentable compromiso moral con la democracia. Y sin embargo, al actuar así, tanto los consejeros electorales como los magistrados se volverán cómplices del inminente colapso de la transición democrática en México o, para ser más precisos, de la instauración fallida de la democracia. 


\section{I. ¿POR QUÉ FRACASAN LAS TRANSICIONES?}

La transición mexicana a la democracia ha sido tan peculiar en su evolución y desenlace que muchos analistas prefieren desechar las teorías de las transiciones por considerarlas inaplicables al caso mexicano. Sin embargo, proceder así es sólo un artificio para evitarse la tarea de pensar con el rigor que exige el empleo de este corpus teórico, producto de años de investigación y miles de estudios de casos en todos los continentes. Además, desentenderse de esta teoría argumentando la especificidad del caso mexicano es una falacia, por cuanto cada proceso en consideración es único e irrepetible. De lo que se trata más bien es de enriquecer o depurar la teoría a partir de las particularidades de cada caso. Ciertamente, Se puede estar de acuerdo o no con esta literatura, pero si se emplean sus categorías para caracterizar un proceso específico, deberían al menos emplearse con rigor y evitarse así especulaciones insustanciales y arbitrarias como las muchas que abundan entre los especialistas en México. En lo personal, he externado en varias ocasiones mis diferencias con la teoría de las transiciones, ${ }^{1}$ pero a la hora de utilizar sus conceptos prefiero ceñirme a sus indicaciones antes que especular y alimentar la confusión. Dicho de otra manera, estudiar un proceso de transición específico con las categorías de la teoría de las transiciones no es un ejercicio arbitrario de imaginación o interpretación, sino uno riguroso de caracterización a partir de datos duros en el que no hay espacio para ocurrencias ni posicionamientos políticamente interesados. Eso corresponde más bien a los políticos profesionales, no a los académicos. ${ }^{2}$

Dicho esto, la pregunta inevitable para quienes nos ocupamos de estudiar la política y la democracia en México es: ¿en qué momento de la transición a la democracia nos encontramos hoy, después del inminente regreso del PRI al poder por la vía electoral? Más específicamente: ¿el retorno del PRI al poder significa una restauración autoritaria, una regresión o es simplemente una alternancia de regreso en la que no se ponen en riesgo los avances democráticos alcanzados hasta ahora?; ¿en caso de una regresión autoritaria existen o no suficientes indicios para suponer que se trató de una regresión pactada, o sea que contó con el consentimiento de actores políticos clave?; y, adicionalmente, ¿qué papel desempeñan hoy las autoridades judiciales electorales en el derrotero que puede seguir nuestra democracia en el futuro inmediato?

\footnotetext{
${ }^{1}$ Véase, por ejemplo, Cansino (2008 y 2009a).

${ }^{2}$ El tema de la transición en México ha sido tan manoseado por todos (intelectuales, académicos, políticos, periodistas, analistas, etcétera), más con fines políticos que heurísticos, que ha terminado por ser uno de esos conceptos que significa todo y nada al mismo tiempo, por lo que se puede emplear para decir cuanta barbaridad se quiera. A ello ha contribuido no sólo la actualidad del tema, que por ese simple hecho suscita controversias, sino el total desconocimiento o el conocimiento superficial de la literatura politológica sobre el particular. Véase Cansino (2011b).
} 
He estudiado el tema de la transición mexicana en innumerables ocasiones y lo menos que quiero aquí es repetirme. Por ello sólo resumiré algunas cuestiones clave que me permitan aproximarme con mayores elementos a las interrogantes apuntadas arriba, no sin antes remitir a los interesados en el detalle a dichos textos. ${ }^{3}$ En estricto sentido es incorrecto seguir describiendo a México con la categoría de transición, pues ésta concluyó en el 2000 con la alternancia. La explicación teórica es muy simple: una transición culmina cuando sucumben los pilares de dominación que caracterizaron a una determinada forma de ordenación política o régimen político. Sin duda éste es el caso de México, pues con la alternancia del 2000 sucumbieron tanto el partido hegemónico encarnado en el PRI (entendido como un partido no competitivo que basaba su dominio en factores extrademocráticos) como el presidencialismo (entendido como un poder ilimitado con enormes facultades constitucionales y metaconstitucionales), las dos estructuras sobre las cuales se sostenía todo el entramado institucional del viejo régimen priista. ${ }^{4}$ La alternancia en el poder marca pues, el fin de la transición mexicana, una transición muy larga y atípica que tuvo como eje las reformas electorales, dejando intacto el resto del entramado normativo. Dicha apertura limitada y controlada de la arena electoral fue más producto de las exigencias de un régimen autoritario por rasguñar legitimidad por la vía democrática en coyunturas de deterioro o abierta crisis política que de una voluntad democratizadora genuina por parte de las elites priistas. Como quiera que sea, la alternancia tiene lugar en una fase terminal del viejo régimen, atravesado por innumerables conflictos internos e incapaz de neutralizar el creciente repudio social en su contra. Con la alternancia y el fin de la transición se inaugura un nuevo proceso en México que la literatura especializada denomina "instauración democrática". ${ }^{5}$ Dicho proceso puede durar varios años y no hay ninguna seguridad de que culmine con éxito. La instauración democrática consiste básicamente en la derogación inmediata de las leyes y reglas antidemocráticas generadas durante el viejo régimen autoritario ${ }^{6}$ y el diseño

\footnotetext{
${ }^{3}$ Véase, por ejemplo, Cansino (1994, 1997, 2000, 2004, 2007, 2009a, 2009b y 2011a); Cansino y Covarrubias (2006 y 2007) y Cansino y Nares (2011).

"La categoría clásica de "partido hegemónico" se debe a Sartori (1976), la definición del presidencialismo mexicano como un "poder ilimitado con enormes facultas constitucionales y metaconstitucionales" se debe a Carpizo (1978), aunque también resulta ilustrativa la definición aportada por Krauze de "presidencialismo imperial" (2002). Con todo, el primero que sostuvo que el PRI y el presidencialismo constituían los pilares de dominación del régimen posrevolucionario en México fue Cosío Villegas (1972).

${ }^{5}$ Véase, por ejemplo, Morlino (1980 y 2007), Schmitter y O’Donnell (1986) y Cansino (2002).

${ }^{6}$ En transiciones desde dictaduras militares, estos regímenes suelen considerase estados de excepción destinados a disolverse tarde o temprano una vez que se hayan logrado los objetivos que propiciaron su irrupción, como poner orden en la economía, suprimiendo para ello derechos y garantías ciudadanas. Obviamente, este no es el caso del régimen político mexicano posrevolucionario que, sin ser democrático, nunca se concibió como excepcional o transitorio, sino como un régimen formalmente democrático, aunque por sus componentes autoritarios, fuera más bien una "democracia de fachada". Véase Cansino (2009a).
} 
y aprobación de las nuevas reglas y normas acordes con las exigencias de un régimen democrático, o sea la aprobación de una nueva Carta Magna. Cabe señalar que no ha habido hasta ahora ninguna transición democrática exitosa en el mundo que no haya pasado por una reforma integral de su Constitución, expresión normativa de los nuevos impulsos democráticos y renovadores. Como es obvio, en México no se ha podido materializar este requisito para instaurar la democracia y hacer tabla rasa del pasado autoritario. Lejos de ello, los impulsos democráticos surgidos con la alternancia han quedado atrapados en una normatividad obsoleta y predemocrática, alimentando todo tipo de perversiones y contradicciones, como parálisis decisionales, impunidad, abusos de autoridad, discrecionalidad y elecciones poco confiables. Huelga decir que sin una instauración democrática exitosa no se puede aspirar a consolidar la democracia. De hecho, sólo se puede consolidar lo que se instaura, y en México no ha prosperado hasta ahora la reforma del Estado o reforma constitucional que tanto se pregonó en su momento.

Con todo, hasta las elecciones de 2012 no había razones suficientes para decretar el fin de esta etapa o para hablar de una "instauración fallida", si es que vamos a utilizar correctamente las categorías de la teoría de las transiciones. Ciertamente, en ausencia de un rediseño normativo del entramado político-institucional, México se había encaminado durante los años de la alternancia hacia un hibrido entre el autoritarismo y la democracia, un régimen con una democracia electoral visiblemente defectuosa aunque funcional, pero con grandes resabios autoritarios en el ejercicio del poder, cobijados y alentados por la pervivencia de las reglas del juego predemocráticas del viejo régimen. Además, dada la ausencia de referentes alternativos que anteponer a lo que los ciudadanos estábamos atestiguando, muchos comenzaron a dar por normal para una democracia lo que en realidad era un perversión o desviación de la misma. Pero no todo estaba perdido, existía en el país una nueva y vigorosa pluralidad política, elecciones medianamente confiables y en algún lugar dormitaba aún la idea de que para avanzar en la democracia tarde o temprano tendría que reformarse la Constitución. Después de las elecciones del 2012 todo eso quedó en el pasado y no tenemos más remedio que caracterizar el momento político actual como una "instauración fallida de la democracia", con tres posibles consecuencias: a) un impase en la democracia de larga duración; b) un colapso de la democratización en curso; y/o c) una regresión o restauración autoritaria disfrazada.

Para fines de análisis, por instauración fallida se entiende el fracaso del proceso de rediseño institucional y normativo que sentaría las bases del nuevo régimen democrático, ya sea por la imposibilidad y/o el desinterés de los actores políticos de llegar a acuerdos sustantivos en las arenas institucionales de negociación. En estos casos, es frecuente que los actores políti- 
cos, en especial los partidos, atribuyan la falta de consensos entre ellos a la pluralidad de posiciones a veces irreconciliables en el Congreso. Pero esto no deja de ser un ardid, pues la pluralidad constituye más bien un terreno idóneo para que los acuerdos que se tomen, si realmente hubiera voluntad de pactar, contemplen todos los intereses y posiciones presentes en la arena política. En virtud de ello, me inclino a pensar que la falta de acuerdos se debe más bien a cálculos políticos interesados, pues siempre será más rentable para los partidos políticos y los gobernantes moverse en la ambigüedad, la discrecionalidad y la impunidad que consienten las viejas reglas predemocráticas que hacerlo con nuevas más estrictas que inhiban o castiguen severamente ese tipo de conductas.

La tesis de la instauración fallida para caracterizar al México actual se sustenta en los siguientes hechos:

1. Si en tiempos de alternancia, con una nueva pluralidad en el Congreso, con el entusiasmo renovador surgido de la destitución en las urnas de un régimen autoritario de más de setenta años, no pudo concretarse la instauración democrática, o sea el rediseño institucional y normativo del nuevo régimen, esto menos ocurrirá si el PRI regresa a Los Pinos en diciembre de 2012. No ocurrirá por varias razones, pero la principal es que no le interesa. Si hay un partido que se siente cómodo con las reglas del viejo régimen es precisamente el PRI, pues esas reglas no sólo fueron edificadas por este partido para preservarse en el poder, sino que nadie sabe aprovecharlas mejor que él para sus propios intereses. El PRI se siente como pez en el agua con esas reglas y sólo es cuestión de tiempo para que regresen las viejas prácticas clientelistas, corporativas y verticales que tantos beneficios le reportaron en el pasado a las cúpulas del partido.

2. La transición en México ha tenido como eje, antes y después de la alternancia, las reformas electorales, bajo la premisa a todos luces errónea de que bastaba perfeccionar las reglas de la competencia y la participación electoral para edificar una democracia. Es errónea porque un régimen político democrático es un todo integrado donde el sistema electoral es sólo uno de sus componentes. A la larga, de poco sirve pretender apuntalar una democracia con reformas electorales si junto con estas no se modifican cuestiones tan básicas para una democracia como el equilibrio entre los poderes, la forma de gobierno, el federalismo, la procuración de justicia, los medios de comunicación, la rendición de cuentas, entre miles de aspectos más. ${ }^{7} \mathrm{De}$ hecho, no se puede aspirar a consolidar la democracia electoral en ausencia de reformas al resto del edificio normativo e institucional. Huelga decir que

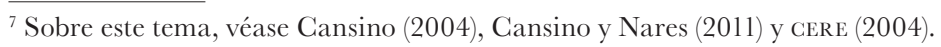


si algo evidenció la elección presidenciales del 2012 fue precisamente el desgaste de la democracia electoral. Si las elecciones permitieron la alternancia en el 2000 con un buen margen de aceptación, hoy sólo producen desconfianza e incredulidad. Tal parece que con la normativa electoral vigente no gana el partido o candidato más votado sino el que sabe aprovecharse mejor de las ambigüedades y vericuetos legales para comprar votos descaradamente, excederse ostensiblemente en los gastos de campaña, comprar encuestadoras para que funcionen como propaganda, comprar medios de comunicación para proyectarse y un sinnúmero de irregularidades más que enlodan y vuelven inequitativa de origen cualquier contienda electoral. A eso hay que sumar la sospechosa actuación del IFE a todas luces parcial y discrecional a la hora de sancionar o no las querellas interpuestas por presuntos delitos electorales. Lo mismo puede decirse del tepjF que seguramente terminará convalidando el cochinero que fueron estas elecciones. Es obvio entonces que si el PRI supo aprovechar esas reglas electorales maltrechas para regresar al poder lo menos que le interesa ahora es modificarlas para futuras contiendas, amén de que este partido contará a su favor con toda la maquinaría del poder, con recursos ilimitados y gran capacidad de movilización, tal y como ocurría en su época más gloriosa. Una razón más que evidente para decretar desde ahora el fin de la instauración democrática.

3. Todo gobierno requiere un umbral de legitimidad para mantenerse sin mayores sobresaltos. Dicha legitimidad puede ser de origen, la que proveen las urnas, o por gestión, la que se alcanza por un desempeño percibido como aceptable por parte de la sociedad. En el caso del próximo gobierno de Peña Nieto, en caso de que el TEPJF convalide su triunfo, es evidente que los cinco puntos de diferencia obtenidos por él en las urnas respecto de su más cercano adversario no son suficientes para legitimarlo, considerando las grandes desconfianzas que suscitó su triunfo entre millones de mexicanos. De ahí que el nuevo presidente buscará invariablemente legitimarse por sus acciones. Ahora bien, si el PRI en el poder actúa como sabe hacerlo para neutralizar los efectos permisivos que heredará de los terroríficos gobiernos panistas, ${ }^{8}$ lo más seguro es que obtenga buenos resultados para legitimarse. Pongo un ejemplo que por lo demás ya fue ensayado por el gobierno de Carlos Salinas de Gortari, que como se sabe es el principal maestro y mentor de Peña Nieto: si el gobierno pacta con alguno o algunos de los cárteles del narco (hoy es vox populi que el principal beneficiario de ese pacto serían "Los Zetas"), se podría "pacificar" el país, disminuir la violencia y el gobierno obtendría cuantiosos recursos provenientes del narco para impulsar políticas

\footnotetext{
${ }^{8}$ Está por aparecer un libro de mi autoría donde evalúo los saldos del panismo en el poder del 2000 al 2012 (Cansino, 2012b).
} 
sociales y económicas de relumbrón. ${ }^{9}$ Por esta vía Peña Nieto obtendría la legitimidad necesaria no sólo para neutralizar parte del descontento que hoy concita sino para desentenderse por completo de la exigencia de legitimarse mediante reformas electorales o reformas al régimen político, tal y como ocurrió con el gobierno de Salinas de Gortari, o sea que contará con un umbral suficiente de legitimidad como para posponer indefinidamente cualquier tipo de reformas democráticas. Es evidente que ese escenario más que factible abona igual que en los puntos anteriores a la tesis de la instauración fallida.

En una perspectiva comparada existen pocos referentes para contrastar el caso mexicano y entender mejor su especificidad. Por lo general las instauraciones democráticas en otras transiciones en el mundo pueden ser incompletas, deficientes, limitadas, parciales, pero rara vez fallidas, pues esto representaría el colapso inminente de las democracia en construcción. El carácter incompleto o limitado de una instauración puede ejemplificarse con algunos casos donde sus reformas a la Carta Magna después de la transición no ocurrieron de golpe sino que tuvieron que someterse a continuos ajustes y revisiones antes de poder aspirar a consolidar la democracia. En América Latina así ocurrió, por ejemplo, en países como Perú, Bolivia y El Salvador, que experimentaron tortuosos y extenuantes procesos de reforma constitucional. Ciertamente, en ninguno de estos casos se puede afirmar que su democracia se haya consolidado, pero sí que ensayaron sendos procesos de reforma integral a sus Constituciones, o sea que sí culminaron con mayor o menor éxito sus respectivos procesos de instauración democrática. En México, por el contrario, la instauración democrática fracasó sin siquiera haberse intentado seriamente, con la consecuencia inédita de instalar al país en una suerte de limbo entre el autoritarismo y la democracia, pero donde las tentaciones restauradoras y regresivas están más vivas que nunca.

Hasta ahora hemos visto que con el retorno del PRI al poder la instauración democrática quedaría trunca por no decir abortada. Pero falta discutir si esto representa o no una restauración o regresión autoritaria.

\section{I ¿ ¿RESTAURACIÓN AUTORITARIA， REgRESIÓN 0 ALTERNANCIA DE REGRESO?}

Teóricamente, la idea de restauración autoritaria alude a un proceso donde se restituyen los componentes fundamentales del antiguo régimen después de un intervalo en el que dejaron de ser operantes. Por su parte, la regresión autoritaria supone un proceso de involución en los avances democráticos

\footnotetext{
${ }^{9}$ Sobre el tema del narco en México, véase Cansino y Molina (2010).
} 
alcanzados en la era postautoritaria, lo que puede conducir al colapso definitivo del régimen democrático que apenas comenzaba a asentarse. Finalmente, la alternancia simple o de regreso significa básicamente que un partido que había sido destituido del poder central por la vía electoral regresa en una elección posterior, en el marco legal establecido y sin que ello represente per se un cambio en el ordenamiento político-institucional. Para variar, considerando estas categorías, el caso mexicano después de las elecciones del 2012 no entra plenamente en ninguna de ellas, sino que tiene un poco de cada una, aunque el desenlace final nos aproxima más a un autoritarismo de nuevo cuño que a una democracia incipiente. Veamos.

Con el regreso del PRI al poder es inevitable que se restituyan muchas de las prácticas autoritarias del pasado, por la sencilla razón de que durante la alternancia no se reformaron las leyes que las posibilitaban y estimulaban en la era autoritaria. Regresarán, por ejemplo, el corporativismo estatal tutelado por el Estado a través del PRI, el clientelismo como un instrumento para obtener apoyos y lealtades a cambio de dádivas, las imposiciones jerárquicas desde el vértice del poder presidencial, el ejercicio discrecional del poder central, entre otras muchas prácticas. Sin embargo, ahora existen ciertos condicionantes para el ejercicio del poder que no había en la era autoritaria y que difícilmente podrían ignorarse sin un alto costo para la legitimidad y la persistencia estable del nuevo gobierno. Se trata de límites específicos que al menos teóricamente nos impiden hablar inequívocamente de una restauración autoritaria, si acaso de una restauración parcial, tales como la existencia de un pluralismo lo suficientemente consolidado en todo el país como para dejarse doblegar por los embates restauradores; una ciudadanía más crítica y participativa que ya no se traga todo lo que le venden sus gobernantes y representantes políticos; una aceptación mayoritaria de la democracia como la vía más pertinente para dirimir los conflictos y elegir a los gobernantes, entre otros aspectos. Quizá todo ello funcione en el corto plazo como un baluarte contra una restauración autoritaria, aunque nada garantiza que así sea, pues el PRI en el poder podría reeditar a su conveniencia elecciones fraudulentas y simuladas semejantes a las que celebraba durante el viejo régimen con tal de mantener sus posiciones de poder. Lo peor del caso es que el PRI ni siquiera tendría que reformar o "ajustar" las leyes electorales vigentes para lograrlo, pues con las que hay es posible cometer impunemente todo tipo de irregularidades e ilícitos, tal y como quedó de manifiesto con las elecciones federales del 2012. Como quiera que sea, mientras ello no ocurra y por más que se reediten muchas de las prácticas autoritarias del pasado, sería impreciso caracterizar el retorno del PRI como una restauración autoritaria.

Dicho en otras palabras, sólo si el PRI optara por reproducirse en el poder mediante elecciones simuladas, inequitativas e impositivas similares 
a las que existían en la era autoritaria, sometiendo el pluralismo político y manipulando la voluntad popular, este partido recuperaría para sí su condición de partido hegemónico no competitivo que lo caracterizó durante décadas, o sea un partido que basa su hegemonía en factores extrademocráticos. Sólo entonces podríamos hablar propiamente de restauración autoritaria. Lo mismo puede decirse del presidencialismo, el otro pilar sobre el que se sostenía el viejo régimen. Sólo en un escenario en que el titular del Ejecutivo recobrara la centralidad incuestionada y todopoderosa de la era del presidencialismo imperial, ya sea imponiendo arbitrariamente su voluntad sobre los poderes Legislativo y Judicial, valiéndose para ello de todo tipo de argucias, chantajes y sobornos (situación por lo demás muy común en los gobiernos estatales donde gobierna el PRI), o actuando arbitraria y discrecionalmente a espaldas de los legisladores y ministros, sin apego a la legalidad y sin ninguna responsabilidad frente a los gobernados, podríamos hablar propiamente de restauración autoritaria. Empero, nadie podría asegurar a estas alturas que este escenario no ocurra ahora que el PRI ha recuperado el poder central.

En virtud de las consideraciones anteriores, la categoría "regresión autoritaria" aplica mejor que la de "restauración autoritaria" para caracterizar el momento que estamos viviendo en México después de las elecciones federales de 2012, al menos por ahora. La razón es simple, mientras la restauración supone el restablecimiento fiel del viejo régimen después de un intervalo postautoritario, o sea la reposición para el caso mexicano de la condición hegemónica del PRI y del presidencialismo sin pesos ni contrapesos reales, la regresión alude simplemente a una involución respecto de los avances democráticos que se habían conquistado, colocando al país en una zona más próxima al autoritarismo que a la democracia. Dicha involución no supone, a diferencia de la restauración, regresar a un autoritarismo idéntico al que existía antes del intervalo postautoritario, sino simplemente colocar al país en una dirección cada vez más distante de la democracia. Sin embargo, mientras se mantenga la remota posibilidad de que el PRI pierda el poder mediante elecciones mínimamente correctas (pedir más a estas alturas, como transparencia, equidad o legalidad, es un eufemismo), la regresión autoritaria que hoy atestiguamos no dejaría de ser una muy sui generis si se consideran adecuadamente las indicaciones que la teoría establece. Me explico, que existen suficientes elementos para hablar hoy, con el regreso del PRI al poder, de una regresión autoritaria, es indudable, pero también podemos estar atestiguando la instauración incipiente de un híbrido institucional muy peculiar entre el autoritarismo y la democracia, igual que el viejo régimen priista, que para entendernos era un régimen formalmente democrático pero autoritario en la práctica. ¿Qué cambia entonces? Si durante los últimos años del viejo régimen lo que teníamos era un autoritarismo en 
transición a la democracia, ahora tenemos una democracia inconclusa en transición al autoritarismo (debido a la instauración fallida). Y respecto a la era de la alternancia postautoritaria, si antes del regreso del PRI al poder el país vivía un proceso de instauración democrática lento y débil, ahora experimenta una regresión autoritaria disfrazada, considerando que la instauración democrática quedará prácticamente confinada por no convenir a los intereses de los nuevos inquilinos en el poder.

Con respecto a la última categoría indicada al inicio, la de alternancia simple o de regreso, es indudable que aplica perfectamente para el caso del retorno del PRI, pues éste ocurrió por la vía de las urnas y en el marco legal establecido para el efecto. Sin embargo, el regreso del PRI al poder no constituye una alternancia más, como cualquier otra, pues lo que regresa es ni más ni menos que el partido que encarna el eslabón con el pasado autoritario. $\mathrm{Ni}$ al caso discutir si hay una ruptura entre el viejo PRI y un supuesto nuevo PRI, pues es evidente que este partido ha sido incapaz de democratizarse y de adecuarse a las nuevas reglas democráticas. Sus dirigentes siguen funcionando con los mismos patrones y esquemas del pasado, pues son exactamente los mismos. En todo caso, la novedad de esta alternancia simple o de regreso radica en el hecho de que restituye en el poder al mismo partido que sometió al país al autoritarismo durante siete largas décadas, cuestión que posee una carga simbólica desconcertante y desmoralizante. De hecho, no existe en el mundo ningún caso semejante en que un mismo partido autoritario regrese al poder por la vía electoral. Nuevamente, México da la nota mundial y demuestra que hay pueblos sin memoria o incapaces de dejar en el pasado sus peores fantasmas y pesadillas, pueblos que entre la servidumbre voluntaria y la libertad eligen penosamente la primera. ${ }^{10}$

\section{I , ¿REgRESIÓN PACTADA O EL MUNDO AL REVÉs?}

Hasta aquí hemos argumentado que con el retorno del PRI al poder no sólo colapsa inequívocamente la instauración democrática sino que nos encaminamos a una regresión autoritaria. Toca dilucidar ahora si existen o no evidencias para sospechar que se trató de una regresión pactada, o sea si el retorno del PRI por la vía electoral contó o no con la complicidad de actores políticos clave de acuerdo a un plan preestablecido. La duda es legítima por cuanto las elecciones del 2012 generan todo tipo de suspicacias dado lo desaseado del proceso, la tibieza y parcialidad del árbitro electoral, el comportamiento insólito de ciertos personajes, la manipulación indiscriminada de las encuestas, entre muchas otras circunstancias irregulares. Aquí sostendré una tesis al respecto, aunque debo admitir que posee un carácter

${ }^{10}$ Sobre el tema de la cultura política en México remito a los interesados a Cansino (2012a). 
altamente especulativo, en espera de mayores datos y pruebas que las disponibles ahora. Propongo pues en lo que sigue un modelo para armar...

\section{INSTRUCCIONES DE USO}

Muchos creen que la política profesional es una actividad para iniciados, por cuanto la mayoría de lo que acontece en sus entrañas, como negociaciones, pactos, intrigas, rupturas, etcétera, es inaccesible o invisible para los ciudadanos. Digamos que el gran teatro político esconde para los espectadores muchos secretos, y sólo alcanzamos a ver lo que los propios actores políticos quieren que veamos de ellos. Sin embargo, en algunas ocasiones, entre acto y acto, se asoman casualmente algunas imágenes o detalles que modifican de golpe nuestra perspectiva inicial. Se trata de situaciones inesperadas que bien miradas e interpretadas pueden esclarecer lo que antes parecía confuso o fragmentario, son como las piezas faltantes de un rompecabezas que sólo al colocarlas en su lugar le dan sentido a la figura hasta entonces incomprensible y confusa.

Sirva esta imagen para ilustrar lo que aquí sostendré sobre la contienda electoral del 2012 en México. A los ojos de muchos, lo que tuvimos fue una contienda normal y sin grandes sobresaltos en la que, a juzgar por las encuestas, uno de los candidatos presidenciales había logrado colocarse muy por encima de sus adversarios en las preferencias electorales, y donde estos últimos hacían esfuerzos denodados por remontar sus posiciones de arranque. Sin embargo, había algunos hechos aislados que parecían no tener mucho sentido y que por lo mismo se perdían en la vorágine de noticias y declaraciones. Así, por ejemplo, puestos como interrogantes, ¿quién filtró a los medios una conversación telefónica privada de la candidata de Acción Nacional, Josefina Vázquez Mota, con la que claramente se dañaría su imagen?; ¿por qué Vázquez Mota parecía desprotegida por sus propios correligionarios, con un equipo de campaña ineficaz y poco profesional?; ¿por qué Vázquez Mota aparecía visiblemente deteriorada en su salud? Y en el caso del candidato de las izquierdas, Andrés Manuel López Obrador, ¿por qué se mostró tan relajado en su campaña, pese a estar tan abajo en las encuestas?, ¿por qué mantuvo tanto tiempo su infecundo e intrascendente discurso de la "reconciliación amorosa", cuando la lógica sugería que debería retomar cuanto antes los contenidos contestatarios y radicales que lo catapultaron hace seis años?, ¿por qué no utilizó a su favor en el segundo Debate Presidencial las evidencias de compra de votos a favor de Peña Nieto ventiladas por el prestigiado periódico británico The Guardian?

\section{LA PIEZA QUE FALTABA}

A primera vista, estas interrogantes pueden parecer irrelevantes y no tener conexión entre sí. Pero un hecho circunstancial nos obliga a reconsiderarlas y redimensionarlas en una perspectiva distinta. Me refiero al fallecimiento 
durante la campaña electoral del expresidente Miguel de la Madrid, y todo lo que este acontecimiento movió entre la clase política.

En primer lugar, llama la atención que los medios de comunicación más importantes e influyentes del país, ya sean electrónicos como escritos, se hayan sumado unánimemente a los reconocimientos públicos que ensalzaban la trayectoria y el legado del personaje. Así, por ejemplo, la idea que deslizaron, apostando a la desmemoria nacional, es que a De la Madrid le tocó gobernar en un tiempo lleno de complicaciones y adversidades, y que pese a ello lo hizo de manera ejemplar, con valentía y patriotismo. Obviamente, eso es insostenible a menos que se violente a conveniencia la historia. Más aún, no hubo un solo artículo editorial en la prensa nacional lo suficientemente crítico que retratara verazmente la triste realidad de aquel sexenio tan deplorable y nefasto para los mexicanos. Lejos de ello, los articulistas más dóciles a la línea de sus respectivos diarios optaron por eximir al personaje de sus desatinos con argumentos tendenciosos y baladíes. Este es el caso de Ricardo Alemán quien escribió en Excélsior que "El PRI tiene en De la Madrid un símbolo poderoso para apuntalar su victoria"; o de la sentida despedida, en El Universal, de Ricardo Raphael De la Madrid a su tío, "Un hombre limpio y honesto que sirvió con coraje a la patria"; o de Sergio Sarmiento en Reforma, para quien "De la Madrid sólo heredó la irresponsabilidad de sus antecesor en el cargo"; o López Dóriga en Milenio, quien consideró injustas muchas de las acusaciones que se prodigan a De la Madrid; o Mauricio Merino, quien en el colmo del paroxismo afirmó en El Universal que "De la Madrid ha sido el mejor presidente de México"; o el propio Carlos Marín, Director de Milenio, quien para quedar bien con toda la "familia revolucionaria", no sólo justificó por razones de salud las acusaciones infundadas de De la Madrid hacia Carlos Salinas de Gortari en recordada entrevista concedida a Carmen Aristegui, sino que reivindicó el legado del propio Salinas de Gortari.

Y aún así, es fácil comprender que los medios de comunicación, en función de sus propias apuestas para el futuro, prefieran quedar bien con el o los candidatos que consideran más seguros con tal de no comprometer los financiamientos y subsidios oficiales. Más específicamente, en plena campaña electoral, criticar a De la Madrid implicaba criticar a Peña Nieto, por sus filiaciones priistas, y de paso ganarse innecesariamente el desaire de éste. Bien explotado por sus adversarios, De la Madrid representaría precisamente, todo lo nefasto que Peña Nieto encarnaba.

\section{ROMPECABEZAS RESUELTO}

Pero si el comportamiento de los medios frente a este acontecimiento tiene sentido por los muchos intereses en juego, que llevan a la sumisión o la lambisconería de los mismos hacia el entonces probable próximo inquilino de Los 
Pinos, alimentando un juego de simulaciones y engaños lo suficientemente sutil como para no evidenciar sus preferencias y perder credibilidad por ello, el comportamiento de actores políticos clave frente al mismo acontecimiento resulta mucho más difícil de desentrañar, como el hecho de que el presidente de la República, Felipe Calderón, se sumara inexplicablemente al cortejo de elogios hacia De la Madrid, al grado de interrumpir una reunión en el extranjero con mandatarios de Norteamérica, y precipitar su viaje de regreso para estar presente en los funerales. Es inexplicable, porque De la Madrid representa todo lo que el panista Calderón combatió en su juventud como opositor al viejo régimen priista: el autoritarismo, la corrupción, la simulación, la demagogia, el encubrimiento... La pregunta clave aquí es: ¿por qué Calderón se sumó a los elogios a De la Madrid, traicionando sus propias convicciones y biografía, aún a sabiendas de que criticar al expresidente y asociarlo con Peña Nieto podía ser capitalizado por la candidata de su partido, desesperada entonces por remontar su desventaja? Obviamente, esta interrogante está conectada con las otras apuntadas arriba, y su adecuada respuesta nos permitirá completar el rompecabezas del proceso electoral.

Sostener que Calderón actuó como lo hizo en razón de su investidura de Jefe de Estado es francamente ridículo, sobre todo porque el presidente no se limitó a hacer una guardia de honor y expresar sus condolencias por el deceso, sino que optó por elogiar públicamente la trayectoria de De la Madrid, aún en contra de sus convicciones de otro tiempo: "Un mexicano ejemplar, creador de instituciones e incansable luchador contra la corrupción". Tampoco resulta convincente el análisis de quienes sostienen, como Ciro Gómez Leyva en Milenio, que "Calderón prefirió la reconciliación sobre el rencor en un acto de gran calado republicano y democrático". No convence porque "reconciliar" sólo puede significar en este contexto redimir al autoritarismo de antaño y mancillar la memoria de varias generaciones de panistas que lucharon contra el viejo régimen. De hecho, ningún panista de cepa le siguió el juego a Calderón. Y mucho menos creíble resulta la versión de José Carreño Carlón en El Universal según la cual el presidente quiso simplemente "mandar un mensaje de civilidad para sentar las bases de un armisticio que tanta falta hará después de la elección”. No es creíble porque la reconciliación no ha sido precisamente una prioridad de Calderón en todo su sexenio. La explicación hay que buscarla pues, en otra parte.

No hace mucho, 22 mil mexicanos interpusieron una demanda ante la Corte Penal Internacional de la Haya contra el presidente Calderón por crímenes de lesa humanidad. Como era de esperarse, la prensa y los medios cerraron filas entonces con Calderón y criticaron acremente esta iniciativa por "insustancial", "ridícula" e "infundada". Hasta el momento, la demanda no ha prosperado y la Corte no se ha pronunciado, pero el hecho reveló intempestivamente a Calderón un escenario trágico más que factible de su 
propio futuro una vez que abandone Los Pinos. No viene al caso discutir aquí la mayor o menor consistencia o pertinencia de la demanda contra Calderón, pero es un hecho que millones de mexicanos se sienten agraviados por la guerra al narcotráfico emprendida por el presidente, que sólo ha dejado a su paso muerte, violencia y luto; una guerra fallida llena de mentiras y engaños, como el número de muertos reportados oficialmente (40 mil) que contrasta visiblemente con la cifra aportada hace poco por el Departamento de Seguridad de Estados Unidos (150 mil), y que para muchos ha sido más un exterminio indiscriminado que un combate entre el Estado y el crimen organizado. Pero es indudable que Calderón no puede tomar a la ligera las muchas señales de malestar que sus malas decisiones han generado y que hacen que su sexenio sea percibido por millones como funesto y criminal.

En esa perspectiva poco halagüeña, a Calderón no le quedaban muchas opciones a no ser que pactara con su sucesor en el cargo inmunidad y protección a cambio de respaldo electoral. Es muy probable que ese pacto se haya sellado durante la contienda, y que el affaire De la Madrid haya sido una muestra clara de la voluntad y el compromiso asumido por Calderón. Obviamente, me refiero a un pacto secreto entre Calderón y Peña Nieto, a quien seguramente Calderón, a partir de sus propias encuestas, ya consideraba su sucesor en el cargo. Hay momentos en la biografía de los líderes en que las convicciones pasan a segundo término para privilegiar pragmáticamente los intereses personales. Calderón terminará su sexenio desacreditado y muy cuestionado, pero por la vía de un pacto con el PRI y Peña Nieto habría logrado, cuando menos, la inmunidad necesaria para su retiro. ¿Descabellado? Para nada. Si alguien ha mostrado ser pragmático y astuto es precisamente Calderón, un político lo suficientemente hábil y perverso para torcer las cosas a su conveniencia.

Con esta pieza se completa el rompecabezas, y lo que antes aparecía caótico se aclara. Es evidente que Vázquez Mota padeció en carne propia la traición de Calderón y con ella la de muchos panistas en los que antes confiaba. El abierto apoyo del expresidente Vicente Fox a Peña Nieto es en ese sentido paradigmático. Más aún, Vázquez Mota fue investigada, espiada y ventaneada por el propio gobierno que decía respaldarla, y se quedó muy pronto sin apoyo suficiente del PAN para armar un equipo mínimamente competitivo para la contienda. No es casual que Vázquez Mota decayera visiblemente en su estado de salud, por más que ella lo disimulara con valentía y coraje. No es casual tampoco que todos los medios de comunicación hayan cerrado filas con el PRI y su candidato. Si alguien tiene clara la película son precisamente los dueños de los medios. De ahí que sólo hay que dejarse llevar tranquilamente por la corriente para llegar a feliz puerto sin sacrificar credibilidad o imagen. Para ello están sus pseudoperiodistas con complejo de estrellas, 
auténticas comparsas del poder y la mezquindad, y las encuestadoras, auténticas prostitutas que se venden sin reparo al mejor postor.

En el caso de López Obrador es difícil creer que su inexplicable tibieza durante la campaña también estuviera pactada. Me inclino a creer que fueron más bien los errores pueriles en su estrategia las que terminaron con sus aspiraciones, igual que en la campaña del 2006. En todo caso, me queda claro que tanto en esas elecciones como en las más recientes, López Obrador fue el enemigo a vencer, primero por el PAN y luego por el PRI, lo que refuerza la tesis en la que creen muchos mexicanos: así como el PRI y el PAN pactaron en lo oscurito la alternancia en el 2000, ahora pactaron el retorno del PRI, y en ambos casos la izquierda y López Obrador no estaban convidados.

\section{ATANDO CABOS}

De ser correcto el razonamiento anterior, estaríamos atestiguando un hecho insólito en la historia de las transiciones en todo el mundo: una "regresión pactada", o sea un acuerdo cupular que posibilita el regreso pacífico y ordenado del PRI al poder (mediante la fórmula de una "alternancia de regreso") por convenir así al presidente en funciones (adquirir de su sucesor el respaldo suficiente para blindarse ante eventuales demandas en su contra). Obviamente, el pacto estaría legitimado por un proceso electoral democrático que definirá a los ganadores y a los perdedores, pero sesgado de origen, y en esa medida impositivo y manipulado, por acuerdos entre las elites políticas. En estricto sentido, como ya vimos, no se trata de una restauración autoritaria, pues restituir el autoritarismo de antaño sería a estas alturas poco rentable en términos de legitimidad para la clase política en su conjunto, pero sí se estaría volviendo a una situación claramente regresiva en que las elecciones no se resuelven exclusivamente en las urnas sino discrecionalmente en los corrillos del poder. Huelga decir que este desenlace es insólito para cualquier transición, pues las involuciones de la democracia al autoritarismo suelen tener como detonante rupturas y crisis, no ocurren de manera pacífica y mucho menos pactada. Pero si nuestra transición ha sido sui generis para todos los efectos por qué no habría de serlo nuestra inminente regresión al prí́smo, disfrazada de democracia.

Ojalá se tratara simplemente de una especulación descabellada, pues aceptarla sería tanto como reconocer una vez más que los ciudadanos sólo somos testigos pasivos de intrigas palaciegas, que la democracia electoral sólo existe para legitimar los juegos de poder más allá del poder, que al menos en estas elecciones todo estuvo cocinado a espaldas de los ciudadanos y que independientemente de lo que hagamos o dejemos de hacer, son los grupos de poder los que terminan imponiéndose de acuerdo a sus intereses. Y sin embargo, cada vez somos más los ciudadanos inconformes con las componendas de los poderosos. Que sepan de una vez los nuevos gobernan- 
tes que gobernarán en el vacío, para una minoría crédula, porque cada vez somos más quienes los despreciamos.

\section{EL PESO DE LAS DECISIONES}

Y así llegamos al momento culminante del proceso electoral del 2012, el momento en que el Tribunal de lo contencioso electoral, el TEPJF, deberá calificar los comicios presidenciales, impugnados por el Movimiento Progresista en vista de las muchas irregularidades que se presentaron. Como decíamos al inicio sólo desde la ingenuidad más rampante se puede pensar que el TEPJF aceptará la querella interpuesta y fallará la invalidación de la elección por anticonstitucional. Este escenario es sumamente improbable porque los órganos electorales actúan movidos por los intereses a los que sirven, o sea los intereses de los poderosos.

Una cosa es cierta, de la decisión del TEPJF depende la suerte no sólo del recambio en el poder sino de la propia transición democrática del país. Calificar la elección minimizando las irregularidades y delitos que se presentaron y que tanto lastiman a la sociedad significaría tanto como decretar la muerte de la instauración democrática, en los términos expuestos arriba. La señal que enviaría el TEPJF es que las elecciones las puede ganar quien aproveche mejor para su causa las ambigüedades normativas e incurra en todo tipo de artimañas para comprar y movilizar votos, a sabiendas de que no serán sancionados, tales como imponer mediáticamente a candidatos, manipular a la población con propaganda encubierta, excederse impunemente en los topes de campaña, triangular recursos con empresas fantasma, etcétera. En ese caso, las elecciones habrán perdido para siempre cualquier rémora de credibilidad como instrumento confiable para elegir a los representantes políticos. Por el contrario, en el remoto caso de que el TEPJF decidiera invalidar la elección y solicitara al Congreso su reposición inmediata, la transición habría alcanzado la madurez necesaria para enfrentar los embates autoritarios y caminar a estadios superiores de legalidad, equidad, civilidad y transparencia. La señal que en ese caso enviaría el TEPJF a la sociedad y a los actores políticos es que ya no se puede aspirar a ganar elecciones al margen de la ley y violentando la voluntad popular, que la ley puede ser ambigua y contradictoria, pero en su seno existen los instrumentos suficientes para impedir excesos y arbitrariedades. En síntesis, si el TEPJF convalida el cochinero electoral con justificaciones legaloides insustanciales tendremos que despedirnos como nación de la democracia y darle la bienvenida a una nueva era de regresión autoritaria con elecciones simuladas e impositivas. Por el contrario, si el TEPJF decide limpiar la elección declarándola inválida se habrá dado un paso histórico que nos aproximaría finalmente al camino mucho más promisorio de la instauración y la consolidación democrática. 
Desde una perspectiva comparada, muchas transiciones a la democracia han debido afrontar un momento crucial del cual dependía condenar al país al estancamiento y la regresión autoritaria o conjurar para siempre los embates autoritarios para finalmente consolidar la democracia. México ha llegado también a ese momento crucial en este 2012 y toca al TEPJF decidir la suerte del país. La decisión en manos del TEPJF es tan importante como la que tomaron en su momento otros países en transición que tuvieron que afrontar con valentía y patriotismo las amenazas autoritarias que se cernían sobre sus jóvenes democracias. Me permito citar tres ejemplos para entender mejor el tamaño del desafío y lo que está en juego en este momento decisivo para la historia de México: las transiciones española, argentina y brasileña.

El 23 de febrero de 1981 tuvo lugar un intento fallido de golpe de Estado en España perpetrado fundamentalmente por algunos mandos militares, cuyo episodio más conocido fue el asalto al Congreso de los Diputados por un numeroso grupo de guardias civiles a cuyo mando se encontraba el Teniente Coronel de la Guardia Civil Antonio Tejero, durante la sesión de votación para la investidura del candidato a la Presidencia del Gobierno, Leopoldo Calvo-Sotelo. Dicha intentona de golpe de Estado se encuentra estrechamente relacionada con los acontecimientos vividos durante la transición española. Guatro elementos generaron una tensión permanente, que el gobierno de la Unión de Centro Democrática (UCD) no logró contener: los problemas derivados de la crisis económica, las dificultades para articular una nueva organización territorial del Estado, las acciones terroristas protagonizadas por ETA y la resistencia de ciertos sectores del ejército a aceptar un sistema democrático. Según el plan trazado por los golpistas, un grupo de guardias civiles armados irrumpió en el Congreso de los Diputados encabezados por Tejero. Éste, desde la tribuna, gritó "iQuieto todo el mundo!” y dio orden de que todos se tirasen al suelo. Como militar de más alta graduación allí presente y como vicepresidente del gobierno, el Teniente General Gutiérrez Mellado se levantó, se dirigió al teniente coronel Tejero y le ordenó que se pusiera firme y le entregase el arma. Tras un brevísimo forcejeo y para reafirmar su orden, Tejero efectuó un disparo que fue seguido por unas ráfagas de los asaltantes. Sin inmutarse, el anciano general permaneció indiferente al sonido de las armas. Mientras la mayor parte de los diputados obedeció las órdenes de Tejero, el diputado Santiago Carrillo y el presidente Adolfo Suárez se mantuvieron sentados en sus escaños. Suárez incluso hizo ademán de ayudar a Gutiérrez Mellado. Durante el asalto, un ayudante de uno de los diputados sufrió un ataque de ansiedad y golpeó a un presente en la nariz. Fueron minutos de gran tensión. Hoy se sabe que con la toma del Congreso y el secuestro de los poderes Ejecutivo y Legislativo, se intentaba conseguir el llamado "vacío de poder", sobre el cual se pretendía generar un 
nuevo poder político de corte franquista. Más tarde, cinco de los diputados fueron separados del resto: el aún presidente Suárez, el ministro de Defensa y presidente de UCD, Agustín Rodríguez Sahagún, el líder de la oposición, el socialista Felipe González, el segundo en la lista del Psoe, Alfonso Guerra, y el líder del Partido Comunista de España, Santiago Carrillo. Aquella noche es recordada como "la noche de los transistores", debido a que la Cadena SER siguió emitiendo y una buena parte de la población la pasó pegada a la radio siguiendo los acontecimientos. A las nueve de la noche, un comunicado del Ministerio del Interior informaba de la constitución de un gobierno provisional con los subsecretarios de todos los ministerios, presidido por Francisco Laína, director de la Seguridad del Estado, para asegurar la gobernación del Estado y en estrecho contacto con la Junta de Jefes de Estado Mayor. Por su parte, el rey rechazó apoyar el golpe lo que permitió abortarlo a lo largo de la noche. El propio monarca se aseguró mediante gestiones personales y de sus colaboradores la fidelidad de los mandos militares. Conjurada la rebelión, y con ella el fantasma del autoritarismo, todas las fuerzas políticas decidieron dejar atrás sus diferencias y cerrar filas para impulsar la democracia. Huelga decir que todos los analistas políticos que han estudiado este acontecimiento histórico coinciden en marcarlo como el inicio propiamente dicho de la consolidación democrática española.

Una situación muy similar se presentó durante la transición a la democracia en Argentina. Entre 1987 y 1989 ocurrieron varios alzamientos militares contra el primer gobierno democrático de Raúl Alfonsín, encabezados por un grupo conocido como "los carapintadas", que se autodefinían como nacionalistas. El mote alude al uso de crema de enmascaramiento facial mimética por parte de los insurrectos, que tomaron varias bases militares y se batieron contra las fuerzas leales al gobierno constitucional en busca de la finalización de los procesos judiciales iniciados contra los protagonistas del terrorismo de Estado durante la dictadura. La rebelión más importante tuvo lugar en la Pascua de 1987, en protesta contra las acciones judiciales llevadas a cabo por el gobierno contra los responsables de los delitos y violaciones a los derechos humanos cometidos durante el autodenominado Proceso de Reorganización Nacional. El mayor Ernesto Barreiro, un elemento de inteligencia que había tenido participación activa en la represión al movimiento obrero y popular en Córdoba, se negó a prestar declaración ante la Cámara Federal de Córdoba en relación a cargos de tortura y asesinato que se le imputaban. Barreiro fue arrestado, a petición del juez competente, por la autoridad militar, y confinado en el Comando de Infantería Aerotransportada 14 del Tercer Cuerpo de Ejército, en la provincia de Córdoba. Cuando la policía intentó hacerse cargo de Barreiro por el desacato a la justicia, el personal del cuartel (130, entre oficiales y soldados) se amotinó, exigiendo el cese de los juicios. Otras dependencias militares se sumaron a la acción, 
ante la férrea oposición de la población civil, en especial las tropas al mando del teniente coronel Aldo Rico (entonces al mando del Regimiento de Infantería de San Javier (Misiones), que se acantonó en la Escuela de Infantería de Campo de Mayo. Los reclamos de los ya apodados carapintadas incluían la destitución del jefe del Ejército (planteando que los jefes que impartieron las órdenes "hoy están en libertad desprocesados, ascendidos y gozando de un privilegio que no merecen") y exigiendo una solución política para los juicios a los represores del proceso y "los del otro bando también". Y decía Rico que "si quienes dieron las órdenes van a la justicia no tenemos ningún problema en ir todos a la justicia, pero ningún hombre de bien que vista uniforme militar puede ampararse escudándose en el sacrificio de sus subalternos". Si bien el alzamiento contó con pocos apoyos públicos entre los responsables de tropa, la actitud del resto de las fuerzas armadas fue unánime: Alfonsín no contó con la subordinación necesaria entre la tropa para sofocar militarmente a los carapintadas. La actitud política y pública frente al alzamiento también fue uniforme. Los principales partidos del país (UCR, PJ, UCD, PDC, PI, PC y PS) suscribieron el "Acta de Compromiso Democrático", oponiéndose a la actitud de los militares pero reconociendo varios grados de responsabilidad en la represión. Este último punto llevó a las fuerzas de izquierda (el MAs, el PCR, el PO y las Madres de Plaza de Mayo) a distanciarse del grupo de los firmantes. Manifestaciones populares se hicieron presentes en Campo de Mayo y la Plaza de Mayo, exigiendo la rendición de los sublevados. Alfonsín marchó a Campo de Mayo para exigir la rendición, en lo que se le cuestionaría luego como un acto de debilidad política. A su regreso, desde el balcón de la Casa Rosada, anunciaría la capitulación de los amotinados. Barreiro huyó, y fue capturado dos semanas más tarde. Tanto él como Rico pasarían a manos de la justicia militar y civil, iniciándole una causa por sedición en los tribunales de San Isidro. A causa de este alzamiento militar, meses más tarde, el gobierno promulgó la Ley de Obediencia Debida, que satisfaría algunos de los reclamos del alzamiento. La ley había sido anunciada por el presidente en el mes de marzo. Independientemente de que el gobierno de Alfonsín tuvo que ceder a algunas presiones de los militares, tuvo la suficiente habilidad para neutralizar el conflicto que amenazaba el orden democrático y de esa manera enfilar a Argentina finalmente hacia la consolidación de la democracia.

El último caso a considerar de transiciones que pudieron enfrentar con éxito los embates autoritarios para consolidar su democracia, es el caso de Brasil con el famoso impeachment o destitución en el cargo de Fernando Collor de Mello, primer presidente de Brasil elegido democráticamente después de la dictadura militar. ${ }^{11}$ De hecho, Collor fue el primer manda-

${ }^{11}$ El impeachment es una figura del Derecho anglosajón (específicamente en Estados Unidos y Gran Bre- 
tario latinoamericano destituido por corrupción en diciembre de 1992. La acusación provino del propio hermano del mandatario, Pedro Collor de Mello, quien abrió la atención con un listado de denuncias que contenía una red de tráfico de prebendas, contratos ilícitos, negocios ilícitos por parte de testaferros, desvíos de fondos, presiones non santas contra el Presidente de Petrobras, beneficios en la privatización de la compañía aérea VASP, y enriquecimiento ostentoso de amigos y colaboradores que habían sido colocados en lugares clave del gobierno, incluido el Banco Central. Asimismo, la primera dama, Rosane Malta, fue acusada de apropiarse de fondos públicos de la Legión Brasileña de Asistencia. La prensa recogía con naturalidad las noticias acerca de la multiplicación asombrosa del patrimonio de los Collor. Eran tantas las evidencias de corrupción que la Cámara de Diputados inició una investigación y confirmó las irregularidades e ilegalidades. Se probaron sobornos a empresarios por favores políticos, depósitos de sumas enormes de dinero negro a nombre de empresas ficticias en paraísos fiscales y transferencias regulares a las cuentas bancarias de testaferros y amigos del poder. En las calles se generó un movimiento permanente de repudio popular, grandes movilizaciones que exigían la inmediata renuncia del presidente. Pero Collor respondía con discursos encendidos de soberbia y decidió convocar a la simpatía de los brasileños sin éxito. Intentó organizar actos políticos de apoyo pagando tamboriles y fracasó rotundamente. Mientras tanto, la inflación crecía al 991 por ciento en agosto de 1992. La Comisión de Investigación de Diputados llegó a acumular un amplísimo expediente de 3 mil páginas y terminó acusando al Presidente con pruebas indiciarias de delitos suficientes para procesarlo y destituirlo del cargo. Entre los documentos, figuraban 40 mil cheques y trece colecciones de extractos bancarios. De esta manera, la democracia brasileña, y en particular el Poder Legislativo, dio una prueba de madurez y civilidad que permitió conjurar los excesos del poder tan frecuentes en el pasado autoritario, y consolidar la democracia por los cauces constitucionales sin emplear violencia alguna.

De esta forma hemos referido tres pasajes de la historia reciente de las transiciones que marcaron la diferencia entre condenar a sus países a involuciones autoritarias o encaminarlas a la consolidación democrática, o sea a estadios superiores de civilidad, legalidad y respeto. En los tres casos, fueron políticos profesionales, partidos, autoridades, legisladores o jueces, los que tomaron en sus manos el desafío y actuaron en consecuencia, con patriotismo y responsabilidad, anteponiendo los valores de la democracia a sus

taña) mediante el cual se puede procesar a un alto cargo público. Para ello, el Parlamento o Congreso debe aprobar el procesamiento y encargarse posteriormente del juicio del acusado (normalmente en la Cámara Alta). Una vez que un individuo ha sido objeto de un impeachment tiene que hacer frente a la posibilidad de ser condenado por una votación del órgano legislativo, lo cual ocasiona su destitución e inhabilitación para funciones similares. 
intereses particulares. Huelga decir que de este tamaño es el desafío que tiene por delante el тEPJF en México a la hora de calificar la elección presidencial de 2012. Si los magistrados actúan con el arrojo y el compromiso inquebrantable con la democracia como lo hicieron sus contrapartes en los casos referidos, o sea si invalidan la elección presidencial por contravenir los preceptos de equidad, limpieza y transparencia emanados de la Constitución, habrán dado un paso histórico para salvar nuestra democracia y la Patria se los premiará perennemente. Caso contrario, si no lo hacen, condenarán penosamente al país a una nueva espiral sin retorno hacia el autoritarismo.

V. AUTO DE FE

No dudo que algunas de las tesis sostenidas en este ensayo generen incredulidad o escepticismo en algunos lectores. A los ojos de muchos simplemente tuvimos una elección más con vencedores y vencidos, con fortalezas y debilidades, con luces y sombras. Nada excepcional. Pero ese es precisamente el problema, o sea creer que estos comicios fueron "normales", pese a las innumerables irregularidades que pudimos atestiguar todos. Esa presunta normalidad es la que nos condena como país al fracaso, la parálisis y la servidumbre, o sea a ser sometidos y ultrajados voluntariamente por los poderosos, por los que tienen secuestrado al país y gobiernan en el vacío, a nuestras espaldas. Por fortuna, hay una masa crítica cada vez más informada y participativa, que duda y resiste, que cuestiona y se confronta. Es ahí y sólo ahí donde cabe hoy alguna esperanza para México.

\section{REFERENCIAS}

Cansino, G. (1994), Construir la democracia. Limites y perspectivas de la transición en México, México, Miguel Ángel Porrúa/CiDE

Cansino, C. (1997), Después del PRI. Las elecciones de 1977 y los escenarios de la transición en México, México, CEPCOM.

Cansino, C. (2000), La transición mexicana, 1977-2000, México, CEPCOM.

Cansino, C. (2002), Conceptos y categorías del cambio politico, México, IEESA.

Cansino, C. (2004), El desafio democrático. La transformación del Estado en el México postautoritario, México, Jus.

Cansino, C. (2008), La muerte de la ciencia política, Buenos Aires, Debate.

Cansino, C. (2009a), El evangelio de la transición y otras quimeras del presente mexicano, México, Debate.

Cansino, G. (2009b), Politica para ciudadanos. Cartografia del presente mexicano, México, UACJ.

Cansino, C. (201 la), El excepcionalismo mexicano. Entre el estoicismo y la esperanza, México, Océano. 
Cansino, C. (2011b), "Como (no) hacer una tesis", ensayo publicado en versión electrónica en: https://textoshereticos.wordpress.com/2011/04/06/ como-no-hacer-una-tesis

Cansino, C. (2012a), El excepcionalismo mexicano. Entre el estoicismo y la esperanza, México, Océano.

Cansino, C. (2012b), México en ruinas. Los saldos del panismo en el poder, 2000-2012, México, BUAP.

Cansino, C. e I. Covarrubias (2006), En el nombre del pueblo. Muerte y resurrección del populismo en México, México, CEPCOM.

Cansino, C. e I. Covarrubias (eds.), (2007), Por una democracia de calidad. México después de la alternancia, México, Educación y Cultura.

Cansino, C. y G. Molina (2010), La guerra al narco y otras mentiras, México, ICI/CEPCOM.

Cansino, C. y G. Nares (2011), La fragilidad del orden deseado. México entre revoluciones, México, BUAP.

Carpizo, J. (1978), El presidencialismo mexicano, México, Siglo XXI.

CERE (2004), Comisión de Estudios de la Reforma del Estado. Conclusiones y propuestas, México, UnAM.

Cosío Villegas, D. (1972), El sistema político mexicano, México, Joaquín Mortiz.

Krauze, E. (2002), La presidencia imperial, México, Tusquets.

Morlino, L. (1980), Come cambiano i regimi politici?, Milán, Franco Agneli.

Morlino, L. (2007), Democracias y democratizaciones, México, CEPCOM.

Sartori, G. (1976), Parties and Party Systems, Cambridge, Cambridge University Press.

O’Donnell, G. y P. Schmitter (1986), Transitions from Authoritarian Rule. Tentative Conclusions about Uncertain Democracies, vol. 4, en G. O'Donnel, P. Schmitter y L. Whitehead (eds.), (1986), Transitions from Authoritarian Rule, Baltimore, John Hopkins University Press, 4 vols. 